Portland State University

PDXScholar

$11-2-1994$

\title{
Familiality of Early Expressive Language Delay: A Sibling Study
}

Carol Lynn Unkefer

Portland State University

Follow this and additional works at: https://pdxscholar.library.pdx.edu/open_access_etds

Part of the Speech and Rhetorical Studies Commons

Let us know how access to this document benefits you.

\section{Recommended Citation}

Unkefer, Carol Lynn, "Familiality of Early Expressive Language Delay: A Sibling Study" (1994). Dissertations and Theses. Paper 5162.

https://doi.org/10.15760/etd.7038

This Thesis is brought to you for free and open access. It has been accepted for inclusion in Dissertations and Theses by an authorized administrator of PDXScholar. Please contact us if we can make this document more accessible: pdxscholar@pdx.edu. 
THESIS APPROVAL

The abstract and thesis of Carol Lynn Unkefer for the Master of Science in Speech Communication: Speech and Hearing Science were presented November 2, 1994, and accepted by the thesis committee and the department.

COMMITTEE APPROVALS:

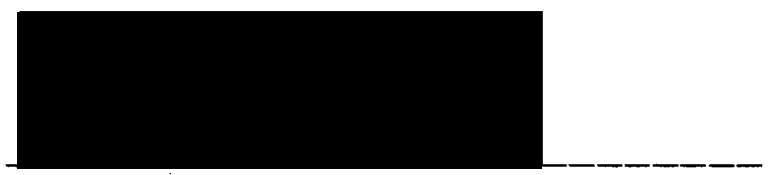

Rhea Paul, Chair

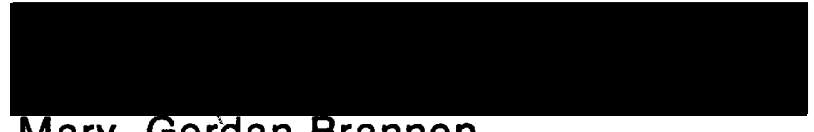

Mary Gordan-Brannon

DEPARTMENT APPROVAL:

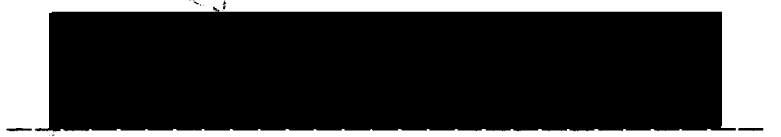

Sorca O'Connor

Representative of the Office of Graduate Studies

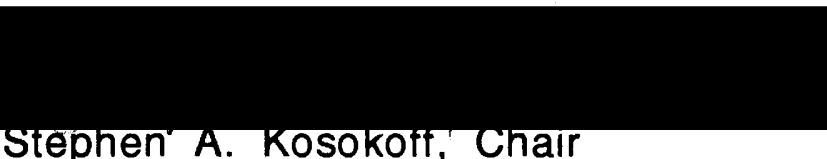

Stephen A. Kosokoff, Chair

Department of Speech

Communication

ACCEPTED FOR PORTLAND STATE UNIVERSITY BY THE LIBRARY by on 28 December 1994 


\section{ABSTRACT}

An abstract of the thesis of Carol Lynn Unkefer for the Master of Science in Speech Communication: Speech and Hearing Science presented on November 2, 1994.

Title: Familiality of Early Expressive Language Delay: A Sibling Study.

Researchers are seeking more information on how and why language disorders tend to run in families, particularly siblings of language disordered children.

The purpose of this study was to examine the prevalence of language and related disorders in the siblings of two groups of children: those with slow expressive language development (SELD) and those with a normal language history. This study sought to answer the following questions: 1) Is there a significant difference in prevalence of language problems in two groups of children: those with SELD and those with a normal language history?, and 2) Is there a greater probability of language problems in the siblings of children in the SELD group who have receptive/expressive language disorders when compared to those SELD children with pure expressive language deficits or to those with a normal language history? 
Subjects were 45 7-and 8-year old children participating in a longitudinal study at Portland State University. The children were divided into two groups, normal and SELD, based on test scores administered at intake to the original study. In order to look at the effect of a receptive component on heritability of language disorders, the SELD group was subgrouped into pure expressive language disorders and receptive/expressive language disorders based on tests administered at intake. A family history questionnaire was the method of data collection, asking parents to report on ten areas of language and related disorders in the siblings of subjects.

Results of one-sided z-tests and a chi-square test were computed and consistently found a highly significant difference between groups, with families of SELD subjects more likely to report a history of language problems over the normal group. These results are consistent with previous research in showing the heritability of language disorders. Results may also indicate that a receptive language component is associated with heritability of specific language disorders among children. 
FAMILIALITY OF EARLY EXPRESSIVE LANGUAGE DELAY:

A SIBLING STUDY

by

CAROL LYNN UNKEFER

A thesis submitted in partial fulfullment

of the requirements for the degree of

MASTER OF SCIENCE

in

SPEECH COMMUNICATION:

SPEECH AND HEARING SCIENCE

Portland State University

1994 


\section{ACKNOWLEDGMENTS}

I wish to thank my committee members, Dr. Rhea Paul, Dr. Mary Gordon-Brannan, and Sorca O'Connor for their assistance with this project. My thesis advisor, Dr. Rhea Paul, was especially helpful in seeing this project to completion. A special thank you to her also for allowing me to be her research assistant for the past 2 years.

A heartfelt thank you to my husband Tom and children Hannah and Kyle for their most valuable support. Without their encouragement, my academic achievement would never have been possible. 
TABLE OF CONTENTS

PAGE

ACKNOWLEDGMENTS

. ii

LIST OF TABLES

CHAPTER

I INTRODUCTION $\ldots \ldots \ldots \ldots \ldots \ldots \ldots \ldots \ldots \ldots$

Statement of Purpose . . . . . . . . . . . . . 3

Definition of Terms . . . . . . . . . . . . 5

I I REVIEW OF THE LITERATURE

Specific Language Impairment Associated

with Adoption-Design Studies

Specific Language Impairment Associated

with Twin Studies

Specific Language Impairment Associated with

Sibling Studies

Family History Studies

Rationale for Present Study

III METHODS AND PROCEDURES $\ldots \ldots \ldots \ldots \ldots \ldots \ldots 18$

Subjects ................. 18

Procedures ...................23

Statistical Analysis . . . . . . . . . . . . . 24

IV RESULTS AND DISCUSSION $\ldots \ldots \ldots \ldots \ldots \ldots \ldots 27$

Results . . . . . . . . . . . . 27

Discussion . . . . . . . . . . . . . . 34

V SUMMARY AND IMPLICATIONS . . . . . . . . . . . . 39 
Summary . . . . . . . . . . . . . . . . . . .39

Clinical Implications . . . . . . . . . . . . .42

Research Implications . . . . . . . . . . . .43

REFERENCES $\ldots \ldots \ldots \ldots \ldots \ldots \ldots \ldots \ldots \ldots \ldots \ldots \ldots \ldots \ldots \ldots \ldots \ldots$ APPENDICES

A OREGONIAN ARTICLE ............. 49

B LANGUAGE DEVELOPMENT SURVEY . . . . . . . . 51

C FAMILY HISTORY QUESTIONNAIRE . . . . . . . . .53

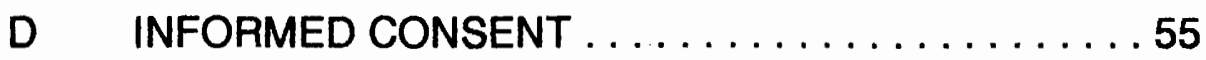

E HUMAN SUBJECTS RESEARCH FORM . . . . . . . 57

F RAW DATA .................... 


\section{LIST OF TABLES}

TABLE

PAGE

1 Demographic Description of Subject Groups at Intake

2 Average age, SES, z-scores, and LDS for 2 Groups ..................... 21

3 Average Performance Scores for 3 Groups at 7-8 Years of Age . . . . . . . . . . . . . 22

$4 \quad$ Family History Questionnaire of Language Problems in Siblings of Study Subjects ..... . 25

5 Frequency and $\underline{z}$-scores of Each of 10 Questions in 2 Groups . . . . . . . . . . . . . 28

$6 \quad$ z-Score and Percent of Families with Affected Siblings in 2 Groups . . . . . . . . . . . . . . . 30

$7 \quad \underline{z}$-Values for Each of 10 Questions on Family History Questionnaire for 2 Groups . . . . . . . . 32

8 3-Way Chi Squared Comparison Between 3 Groups on Each of 10 Questions on Family History Questionnaire ....................33 


\section{CHAPTER 1}

\section{INTRODUCTION}

There has been an interest in finding a genetic basis for specific communication disorders for many years. Researchers have sought evidence to support the notion that language problems tend to aggregate within families (Ludlow \& Cooper, 1983; Tallal, Ross, \& Curtiss, 1989; Tomblin, 1989; \& Whitehurst, Fischel, Arnold, \& Lonigan, 1992). A familial component has been found in schizophrenia, depression, stuttering, dyslexia, and antisocial behavior (Lewis, Ekelman, \& Aram, 1989; Tallal et al.,1989; Tomblin, 1989, \& Whitehurst, Arnold, Smith, Fischel, Lonigan, \& ValdezMenchaca, 1991). These conditions, when concentrated within families, suggest that genes, the environment, or both contribute to the disorder.

Could the same be the case for specific language impairments? As Tomblin (1989) pointed out, few studies have directly addressed this question. Case studies and small group studies have looked for family aggregation of speech deficits and language impairments (Lewis \& Thompson, 1992; Ludlow \& Cooper, 1983). Studies of children who were adopted and studies of twins have attempted to separate genetic influences from environmental factors in the transmission of language disorders. 
More recently, family history studies have looked at familial aggregation of language disorders to support the hypothesis that language disorders are influenced by inherited factors. For example, the brothers of language delayed subjects have shown a significantly greater aggregation of language impairment over a control group of normal subjects (Tomblin, 1989). Results of these studies led most researchers to agree that language impairments tend to run in families (Lewis \& Thompson, 1992; Ludlow \& Cooper, 1983; Tallal et al., 1989).

Whitehurst et al. (1991) pointed out that all of the above studies used a general definition of language impairment that may include articulation/phonological deficits, cognitive/emotional disorders, and receptive/expressive delays. Which specific factors of language impairment are responsible for inherited language delays in siblings of language disordered subjects? This is the question proposed by Whitehurst et al. (1991). These researchers pointed out that much of the research on language delay has failed to subgroup the general category of language disorder in the sample population, stating that "studies of language problems have often aggregated children who may in fact by quite heterogeneous" ( $p$. 1151).

It appears then, that language disorders do tend to aggregate within families, particularly siblings of language disordered subjects. This study addressed the specific questions raised by 
Whitehurst et al. (1991) that suggest language delay may be inherited when the sample population includes a receptive deficit, but not inherited when specific to expressive language. This study examined family history of language disorders in siblings of children with developmental expressive and receptive language delay. Subjects with expressive only and combined receptive/expressive disorders were investigated separately.

\section{Statement of Purpose}

The purpose of this study was to examine the prevalence of language and related disorders in the siblings of two groups of children: (a) those with slow expressive language development and (b) those with normal language development.

The specific questions addressed in this study are:

(a) Is there a significant between-group difference in the number of families with siblings who show language or related disorders when children with slow expressive language delay are compared to those with normal language history?

(b) If the answer to question 1 is yes, is there a greater probability of family history in subjects with both receptive and expressive problems, when compared to those with expressive deficits only?

(c) Is the same true when compared to those with a normal language history? 
The hypothesis for the first question is: The proportion of children with slow expressive language development who have a sibling with language delay is significantly greater than the proportion of children with normal language history who have a sibling with language related problems.

The hypotheses for question 2 are: (a) The proportion of children with slow expressive language development, including a receptive and expressive component, who have a sibling with language delay is significantly greater than the proportion of children with expressive deficits only and; (b) the same is true when compared to a group with a normal language history.

These in turn led to the following null hypotheses: (a) There will be no significant difference in the proportion of families with siblings affected with language and related problems between the two groups; (b) There will be no significant difference in the proportion of siblings with language and related problems between those subjects with expressive/receptive delays and those with expressive deficits only, and (c) when compared to the siblings of subjects with a normal language history. 
Definition of Terms

The following operational definitions were used for this investigation:

Expressive Language Delay (ELD): a term used to describe a condition characterized by severe delays in the development of spoken language compared with receptive and cognitive abilities (Whitehurst et al., 1991).

Specific Language Impairment (SLI)/Specific Language Disorder (SLD): terms used to describe a condition characterized by poor language skills in association with normal hearing and nonverbal IQ.

Slow Expressive Language Development (SELD): a term used to describe children whose expressive vocabulary at 24 months of age was less than 50 words or no two-word combinations at 24 months of age.

Family History: a term used to describe parent report of late talking, speech, language, and/or school problems in the siblings of children with slow expressive language development or in those with a normal language history. 
CHAPTER II

\section{REVIEW OF THE LITERATURE}

It has been found that $8 \%$ to $15 \%$ of all preschool children have some type of speech and/or language disorder (Tallal et al., 1989). Some of these disorders are acquired through sensory loss or dysfunction and some through conditions such as mental retardation, neurological problems, or brain injuries (Tallal et al., 1989). According to Tallal et al. (1989), etiology of others is less clear and are often called developmental or specific, in which symptoms and causes are less well defined.

A search for possible genetic factors of developmental language disorders has been occurring for a long time (Ludlow \& Cooper, 1983; Tallal et al.,1989; Tomblin, 1989; Whitehurst et al., 1992). A higher incidence of developmental speech and language impairments in the relatives of children with language impairments has been reported in current literature (Neils \& Aram, 1986; Tallal et al., 1989; Tomblin, 1989; \& Tomblin, Freese, \& Records, 1992). According to Tomblin et al. (1992), recent data suggest that "specific language impairment aggregates in families" (p. 832).

How can this pattern of inheritance be explained? To answer this question, studies have examined the family histories of individuals with language disorders looking for a genetic basis for 
specific language impairments. Results of twin studies and studies of adopted children have linked genetic influences in disorders such as schizophrenia, depression, stuttering, and anti-social behavior (Lewis et al., 1989; Tallal et al., 1989; Tomblin, 1989; Whitehurst et al., 1992). Case histories of developmental language disorders have reported significantly higher prevalence rates of family members also affected with language problems, dyslexia, and learning disabilities (Lewis et al., 1989; Matheny \& Bruggemann, 1973; Neils \& Aram, 1986; Tallal et al. 1989; \& Tomblin, 1989) than those seen in the general population. Small group studies of developmental language disorders have reported similar results, thereby suggesting a genetic or environmental basis for some types of language disorders (Talial et al., 1989).

Do all forms of developmental language disorder cluster within family units? This is the question proposed by Whitehurst and associates (1991 \& 1992) who asserted that speech problems and receptive/expressive language delays have been undifferentiated in the sample population of studies addressing the etiology of language delay. These researchers found no significant familial aggregation in a sample population of children with language delay specific to expressive language. Their research raises issues regarding the influence of receptive and expressive factors on the inheritability of developmental language disorders. 
Specific Language Impairment Associated with Adoption-Design Studies

It has been stated that some speech and language disorders, such as stuttering and reading disabilities tend to run in families (Lewis et al., 1989; Neils \& Aram, 1986). Ludlow et al. (1983) stated, however, that by studying the family, it is not possible to determine the greater influence, that is, heredity or environment, because both are shared by family members.

One way to discriminate environment from genetic influences is the adoption design study, where both factors are investigated at separately. This type of design includes the biological parents, the parents who adopt the child, and the child. It allows for identification of specific environmental influences on development, an advantage over other methods, according to Hardy-Brown, Plomin, and DeFries (1981).

An adoption design study was employed by Hardy-Brown et al. (1981) to investigate heredity and environmental differences in the rate of communicative development of 50 adopted 1-year-old children. Cognitive abilities of the birth mother, specifically memory skills, and the communicative performance of the adopted child were found to be significantly related. This did not prove to be significant for the adoptive parents, leading these researchers to suggest that biological influences contribute to the communicative 
development of children in the first year of life. The study lends evidence to the theory of a genetic influence to language development.

Specific Language Impairment Associated with Twin Studies

Twin studies are another way to separate the two variables of genetics and environment. A twin design compares the characteristics of identical and fraternal twins. Identical, or monozygotic $(M Z)$, twins are genetically alike and any differences in are thought to be from environmental factors. Fraternal, or dizygotic (DZ), twins share approximately $50 \%$ of the same genes, having developed from two separate ova, with differences between twins considered to be from both environmental and genetic factors (Lewis \& Thompson, 1992; Mather \& Black,1984).

According to Lewis \& Thompson (1992), twin design studies have reported higher concordance rates in $M Z$ twins than in same-sex DZ twins in the disorders of dyslexia and stuttering. These authors examined speech and language disorders in 57 same-sex twins via a questionnaire format and without direct testing of subjects. This preliminary investigation included $32 \mathrm{MZ}$ and $25 \mathrm{DZ}$ twins, finding a higher concordance for speech and language disorders in the $M Z$ group than in the $D Z$ group, $86 \%$ to $48 \%$ respectively, suggesting a strong genetic factor. Brothers of those in the disordered group were the 
most affected. This preliminary study lends support to earlier studies positing a familial component in developmental language, learning, and speech disorders in families of twins (Lewis et al., 1989; Tallal et al., 1989; Tomblin, 1989).

A study by Matheny and Bruggeman (1989) looked at normal speech and language abilities in the area of articulation, finding that language development of twins is more alike than siblings who are not twins. The authors noted incidences of articulation problems among identical (MZ) twins, reporting that articulation disorders of the same type are usually found in both twins. This follow-up study looked at the articulation skills of 64 identical (MZ) twins, 37 fraternal (DZ) twins, and 94 siblings of twins. Within-pair correlations for articulation scores ranged from .54 to .68 for the $D Z$ twins and .84 to .90 for the $M Z$ twins. Results from this study led the authors to conclude that the more closely the children share the same genetic make-up, the more closely they resemble each others' speech patterns. Other areas of similarities related by Matheny and Bruggeman (1989) showing a positive influence of genetic factors include intelligence, cognitive abilities, and sound discrimination ability in the areas of pitch and phonemes.

A study seeking to identify the hereditary aspects of several language skills was conducted by Mather and Black (1984), who looked at 158 pre-school aged twins. Both identical (MZ) and fraternal (DZ) twins were included. The language skills of comprehension, verbal expression, semantic knowledge, syntax, and 
sentence length were examined. Data from their study showed a significant influence of heredity in the area of verbal comprehension, leading the authors to suggest that this skill may be the one biologically determined basis for language acquisition. Whitehurst and associates (1992) concurred with the results of this study, stating that "Language impairments that involve receptive delays may have genetic determinants, while expressive language delay (ELD) may not" (p. 279).

Specific Language Impairment Associated with Sibling Studies

Lewis et al. (1989) studied articulation and phonological skills in siblings of speech delayed children. Their research offered evidence in support of the theory that language disorders are not randomly distributed across families, but tend to concentrate within families. Their study used direct testing to classify four groups of subjects: children with phonological disorders and their siblings, and matched normal phonologically developing subjects and their siblings. Higher incidences of reported language disorders were found in the siblings of the speech disordered group, $12.4 \%$ versus $2.3 \%$, respectively. This group differed from the siblings of the normal group in the specific areas of phonology and reading, indicating a familial contribution in these areas. 
Family History Studies

Several authors have used family history information from parents to report instances of speech and language disorders among family members (Lewis et al., 1989; Tallal et al., 1989; Tomblin, 1989; Matheny \& Bruggemann, 1973; Neils \& Aram, 1986). From their data, Neils and Aram (1986) showed an average percentage of language-impaired family members in a group of individual cases with language impairments to be $20 \%$ versus $3 \%$ in a control group. This study compared parent report of family histories of language disorders, including speech problems, stuttering, and reading disorders, between 74 language impaired children to a control group of 36 normal children. The siblings of the children with specific language impairment were directly tested. Of all family members, parents were more frequently affected, with the highest being fathers at $58 \%$. The normal group was found to have fewer reported cases of language disorders, lending credence to the theory of a genetic link of language disorders within family members. A high percentage $(38 \%)$ of family members reported impairments that were different from the child's impairment, leading the authors to conclude that environmental factors alone do not explain the high incidence of language-related disorders among relatives of children in the study.

A study by Tallal et al. (1989) used self-report data from families participating in a longitudinal study of developmental 
language disorders (Tallal et al., 1989). First and second degree relatives of 54 language impaired 4-year-olds were studied along with 60 matched controls. Both groups were identified via direct testing of subjects. The disordered group included expressive and receptive language delays, with $60 \%$ presenting articulation deficit in addition to language delay. History data were collected for both biological parents including language problems, school achievement in math, reading and writing, and being retained one grade in school. Results found impaired children more likely to have a positive family history of developmental language disorders than the control group, $77 \%$ to $46 \%$ respectively. The authors related that a family history of developmental language impairment rarely presents as an "isolated" case.

Results of a study by Tomblin (1989) supported existing knowledge and pointed to a strong familial association for developmental language disorders that is not randomly distributed. Using a questionnaire directed to families of two groups of 2 nd grade children; those diagnosed with specific language disorder, defined to include learning disabilities, receptive/expressive language delays, and/or phonological deficits; and a matched control group. Tomblin (1989) gathered information on immediate family members of both groups of children. Tomblin (1989) reported a risk factor for language disorders in the language disordered group to be 9 times greater than in the control group. Data from this study found a high risk group to be the brothers of the language disordered 
subjects, having nearly 30 times the risk for a language disorder than brothers from the normal group. In reporting conclusions drawn from this study, Tomblin (1989) related that developmental language disorders are ". . . attributable to one or more mechanisms associated with the family" (p. 54).

Whitehurst et al. (1991) looked for a genetic basis of language disorders via the family history format, expecting results to concur with those of Tallal et al. (1989). Both studies were similar in sample size and use of a questionnaire format to assess family history of speech, language, and school problems. In contrast to Talllal et al. (1989), however, this study consisted of a sample population of language delay specific to expressive language. Data were gathered on 117 children, 62 were classified via direct testing as expressive language delayed (ELD), with normal receptive language skills and cognitive abilities. The remaining 55 children served as the control group. Both groups were assessed at the average ages of 24 months, 34 months, and again at 44 months. Parents were asked to report a history of late talking, speech problems, or school problems on the immediate family members (parents and siblings) and extended family members (grandparents, aunts, uncles, and cousins). Results showed no significant difference across comparisons of family members for a history of late talking, speech, language, or school problems.

Whitehurst et al. (1991) argued that the discrepancy between the findings of these studies is directly due to the nature of 
language impairment of the affected children. Tallal et al.'s (1989) sample population included expressive and receptive language delays, along with articulation problems. The delayed group of subjects studied by Whitehurst et al. (1991) consisted of children with language delay specific to expressive language, with normal receptive and cognitive abilities. These researchers related that the etiology of expressive language delay may be different depending on the type of language disorder included in the sample population. Whitehurst and associates (1991) suggested that some "general" forms of language disorder, such as expressive/receptive impairments, articulation/phonological problems, and/or cognitive deficits may be inherited, while specific forms such as pure expressive delay may not. In referring to results of their study, Whitehurst et al. (1991), pointed to the need of "careful subtyping" when doing research on language disorders, viewing language and speech impairments as separate disorders.

Rationale for the Present Study

Studies of adopted children and twin studies have shown a hereditary component to general speech and language disorders, supporting the theory of a genetic influence to language development. Family history studies have reported a higher incidence of developmental speech and language impairments in the relatives of children with language disorders. A particular high risk 
group was found to be the brothers of the language disordered subjects.

All but one of the studies mentioned have reported a significant difference between two diagnostic groups, normals and language disordered, and related a higher incidence of language disorders in the families of the language disordered children. Whitehurst and associates $(1991,1992)$ disputed these findings, pointing out how research has thus far failed to separate language delays from speech disorders, such as stuttering and phonological/articulation disorders, along with receptive and expressive language delays.

Methods and subjects of this study are most similar to the study by Whitehurst et al. (1991). Both studies look at family history of language impairments. Subjects of both studies participated in a longitudinal research project. Parent report of a history of language, speech, and school problems is the format of data collection. Both studies consist of a delayed group and a control group of similar age children identified via direct testing. Both studies look at inheritability of language disorders in siblings of the normal and delayed subjects. Whitehurst et al.'s (1991) study focused on subjects with expressive deficits only, finding no significant difference in the proportion of siblings affected with language disorder. This study investigated the influence of expressive/receptive factors on inheritability of language disorders. 
From the literature, it can be concluded that questions have been raised by the various studies mentioned. Separating environment from genetic factors and the use of direct testing of subjects was not addressed by this study. As Tomblin (1989) reported, brothers of language disordered children appear to be particularly at risk for language disorders. This study sought to test further for the presence of specific language disorders, focusing on brothers and sisters of the normal and delayed subjects. Receptive and expressive data from the specific language disordered children were looked at to determine if a significant difference exists between the number of siblings reported with language disorders. Addressing questions raised by Whitehurst et al. (1991), further subtyping of the sample population into expressive only and mixed expressive/receptive delay groups was done to determine heritability influences. 
CHAPTER III

\author{
METHODS
}

Subjects

The subjects for this longitudinal study of "Late Talkers" include 57 children between 20 and 34 months of age at intake (Paul, 1991). The subjects were recruited from local pediatric offices and newspaper advertisements (Appendix A). They were divided into two groups. One group of 27 children was identified as the control group, and the second group of 30 children was identified as "Late Talkers", having slow expressive language development (SELD). Late talkers were defined as those children who at 20-34 months of age produced fewer than 50 different words or no two-word combinations by parent report on Rescorla's (1989) Language Development Survey (LDS) (Appendix B). The control group of 27 children had expressive vocabulary development at 20-34 months of age that exceeded this criterion on the LDS. The LDS was used at intake to measure expressive vocabulary size and is a checklist of 300 of the most common words in children's early vocabularies. It has been shown to have high reliability, validity, sensitivity, and specificity for identifying language delay in toddlers. 
The control group was matched to the SELD group on the basis of age, sex ratio, and SES (see Table 1).

Table 1

Demographic Description of Subject Groups at Intake

Mean Age Total Sex Ratio

Group Number Age at Range Number of SES Intake at Intake Siblings Subjects

Normal 2127 mos. $21-34 \quad 33 \quad 7 F / 14 M \quad 2.71$ * mos.

Delayed $24 \quad 25.8 \quad 20-33 \quad 35 \quad 4 F / 20 M \quad 2.83^{*}$ mos. mos.

*Based on a four-factor scale of 1 to 5 with 1 being the highest socio-economic status and 5 being the lowest (Myers \& Bean, 1968).

The current study examined siblings of subjects in the original study. Only full siblings were included. Of the 30 children in the SELD group, 6 subjects did not have siblings and thus were not included, leaving 24 subjects with 35 siblings. Of the 27 subjects in the control group, 6 were not included because they did not have siblings, leaving 21 subjects with 33 siblings. 
For the present study, subjects with a history of SELD were divided into two subgroups: those with expressive only language delays and those with mixed receptive/expressive language delays. The Reynell Developmental Language Scale (1985), Verbal Comprehension Subscale, was used to assign subjects to these subgroups. The Reynell Developmental Language Scale has been found to have high reliability, concurrent and predictive validity for identifying language ability in children. Scores of more than one standard deviation below the mean were used to identify four SELD subjects with a receptive deficit. These four subjects comprised the receptive/expressive group. The remaining 20 SELD subjects had scores of within 1 standard deviation of the mean for their age and comprised the expressive group. (see Table 2).

The Test of Language Development Primary-2 (TOLD-2) (1988) were administered to the subjects as a direct measurement of their receptive language development when the subjects were approximately 7 years of age. Scores on the Listening subtest are given in Table 3 . It is important to note that receptive language scores, based on the TOLD-2 did not differ among groups, with receptive language quotients in the average performance range of 90-110. This indicates the profile of receptive language performance among study subjects to be more similar by age 7-8 years than it was at intake at age two (see Table 3). 
Table 2

Average Age, SES, z-scores, and LDS For 2 Groups

$\begin{array}{cccccc} & & & \text { Average } & \text { Aver age } \\ \text { Goup Number of } & \text { Average age } & \text { Average } & \text { Reynell } & \text { number of } \\ & \text { Subjects } & \text { in months } & \text { SES } & \text { Receptive } & \text { words on } \\ & & & \text { z-score } & \text { LDS }\end{array}$

SELD

Express

20

24.8

2.8

${ }^{*} 0.61$

22.85

Delayed

SELD

Recep/

Express

4

24.0

3.0

$*-1.9$

13.25

Delayed

${ }^{*}$ Represents number of standard deviations from mean 
Table 3

Average Performance Scores For Three Groups at 7-8 Years of Age

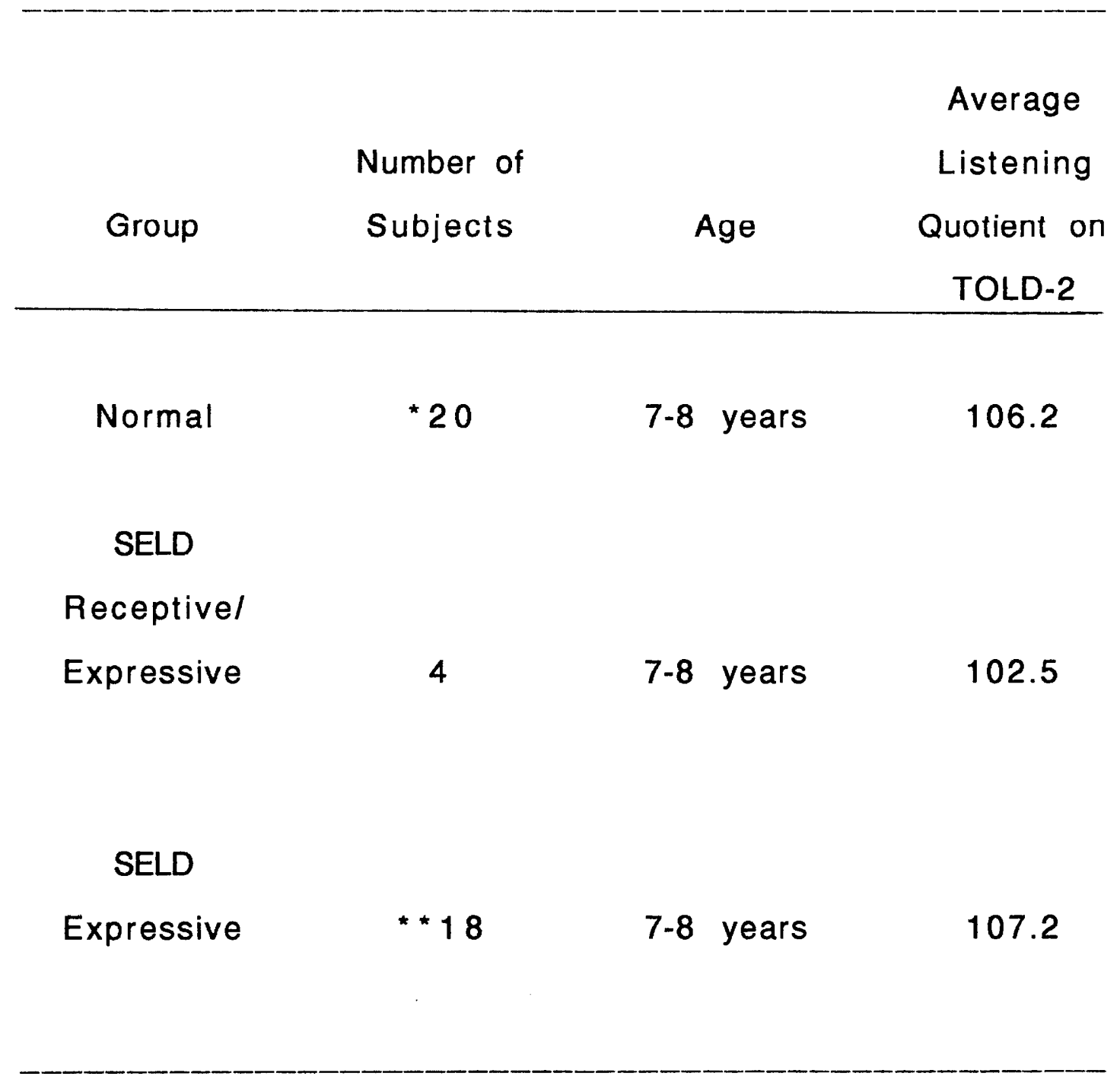

*One subject in this group did not participate in study this year.

**Two subjects in this group did not participate in study this year. 
Procedures

In 1993, when the two groups of children were approximately 7 years of age, their parents were contacted by mail and sent a family history questionnaire and an informed consent form (Appendix $C$ and D). Approval was received from the Human Subjects Research Review Committee (Appendix E). This instrument asked the parents to identify the number of the child's brothers and/or sisters and which of these siblings have shown the following language and related disorders:
1. slow to start talking
2. had speech therapy before entering school
3. trouble learning to put words together
4. trouble pronouncing words/hard to understand
5. trouble learning to read
6. trouble learning to write
7. trouble learning to spell
8. trouble learning mathematics
9. held back a grade
10. received special services in school

Thirty-three parents responded to the first mailing. The remaining 12 parents were contacted by telephone at which time the questionnaire was read and responses to each question were recorded on individual forms. 
The 45 parents' responses were collected and analyzed by comparing the groups used to the original study: 21 families of normal subjects and 24 families of SELD children. The SELD group was subgrouped according to scores on the Reynell Developmental Language Scale (Reynell, 1984), which was administered at intake, when the subjects were approximately 24 months of age.

For this analysis, a language problem is defined as a parent report of 1 or more siblings presenting a history of speech and/or language problems on the 10 questions of the family history questionnaire. The 10 questions gather information on speech, language, and the academic areas of learning to read, write, spell, and learn mathematics (see Table 4).

\section{Statistical Analysis}

A one-sided z-test of proportions was used to compare the proportion of families with affected siblings in the two groups on each question of the family history questionnaire. Following the procedure used by Tallal et al. (1989), responses were labeled for each of the 10 questions listed to account for families with different numbers of siblings. A one was used to indicate a parent response of one or more siblings with a positive history. A zero was used to indicate a parent report that none of the subjects siblings had a positive history of language delay. Only full siblings were included in the study results. 
Table 4

Family History Questionnaire of Language Problems in Siblings of Study Subjects

Number

Question

1

How many brothers/sisters does subject have?

2

How many were late to start talking?

3

How many had speech therapy before entering school?

4

How many had trouble learning to put words together to make sentences?

5

How many had problems pronouncing words

and/or were hard to understand?

$6 a$

Those siblings of school age, how many had

trouble learning to read?

$6 b$

How many had trouble learning to write?

$6 c$

How many had trouble learning to spell?

$6 d$

How many had trouble learning mathematics?

$6 e$

How many were held back a grade in school?

$6 f$

How many received special services in the

schools? 
A significant between-group difference with found, so a Fisher's Exact Test was used to further examine the SELD group. This group was subdivided into 2 groups: those with receptive/expressive language delay at intake and those with pure expressive language delay at intake. Overall responses to the family history questionnaire were looked at to determine that a receptive component influences reported history of language delay in siblings of study subjects.

Lastly, a chi-square test for differences was used to compare the frequency of language history among siblings of three groups; SELD with receptive/expressive delay, SELD with expressive delay, and the normal group of subjects. This insured that the prevalence of language delay in the siblings of SELD subjects with receptive/expressive language delay was different from that of the SELD expressive delayed group and also from the normal speaking group. 


\section{CHAPTER IV}

\section{RESULTS AND DISCUSSION}

Results

The first question posed in this study concerns whether there is a between-group difference in the number of families with siblings who show language or related disorders when children with slow expressive language delay (SELD) are compared to children with normal language history. In computing results, only full siblings were included. The normal group comprised 21 subjects and the SELD group had 24 subjects.

A one-sided z-test was used to look at the proportion of families with affected siblings for each of the 10 questions on the family history questionnaire. Responses were labeled as $0=$ no sibling with reported positive history and $1=0$ ne or more siblings with reported positive history to give equal weight to families of different size. Results show a significant difference, at the .057 level of confidence, of siblings in the SELD group to have speech therapy before entering school (question 3). No significance was found for the remaining 9 questions (see Table 5).

Since a significant difference between groups was found, the second question was addressed. It asks if there is a greater probability of family history of language problems in SELD subjects 
Table 5

Frequency and z-Scores For Each of 10 Questions on Family History Questionnaire in Normal and SELD Groups

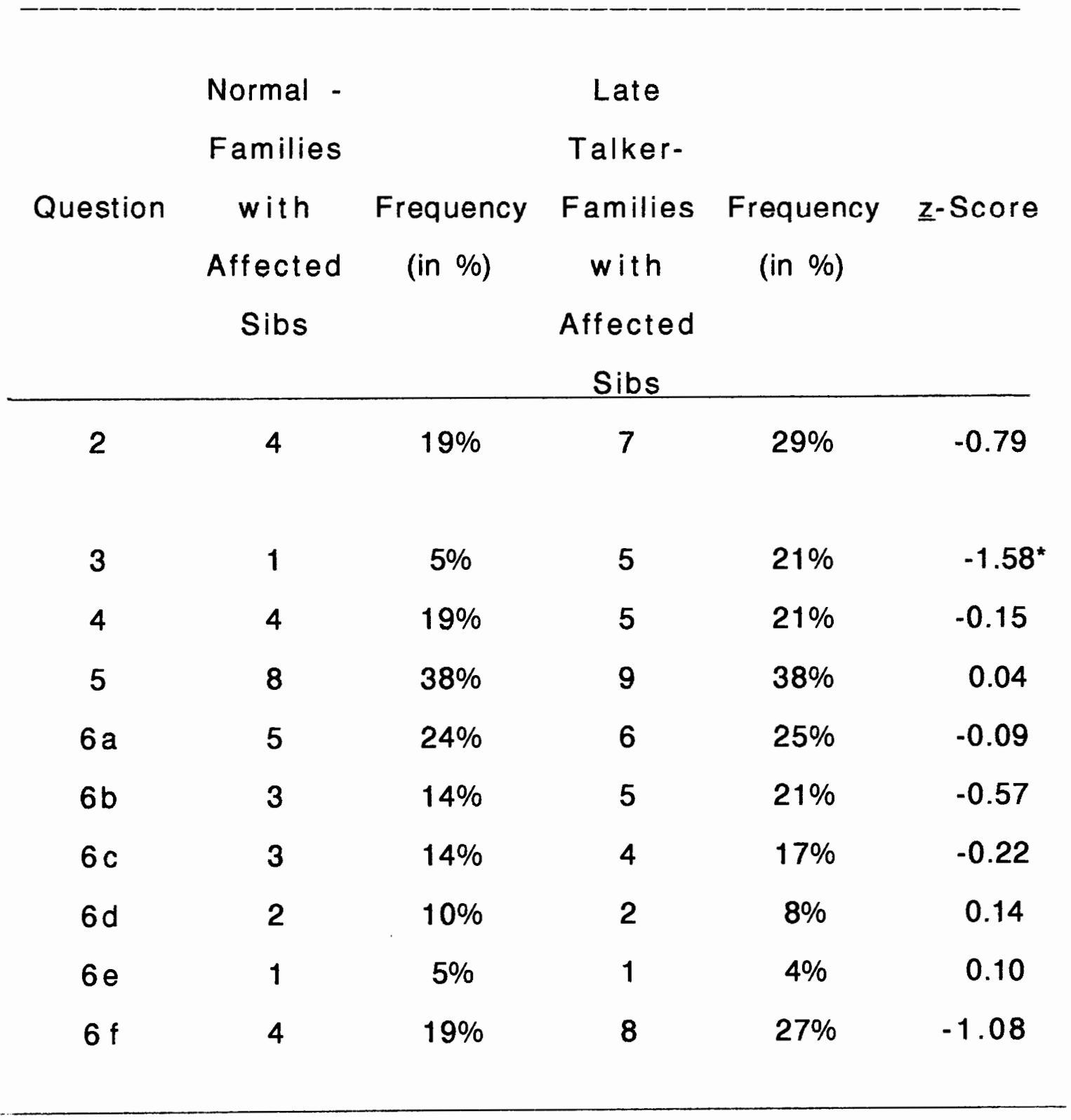

*Significant at the .057 level of confidence. 
with receptive/expressive language disorder compared to SELD subjects with pure expressive language deficits. The two SELD subgroups, receptive/expressive delayed and expressive delayed only, were compared. Parent responses to the family history questionnaire were tallied for each subject, for a total number of families with affected siblings in each of the two subgroups of SELD subjects. In order to account for families of different size, responses were labeled as 0 or 1 . If parents responded to the questionnaire by saying no siblings were affected on any of the 10 questions, a score of 0 was given for that subject. If parents responded to the questionnaire by saying that one or more siblings were affected on any of the 10 questions, a score of one was given for that subject. The scores were then tallied for a total number of families in each group who had any sibling affected on any question.

The data were analyzed with a one-sided z-test. Results show siblings of the SELD subjects in the receptive/expressive language delayed group are more likely to be affected with language problems than those from the SELD expressive only group (see Table 6).

In addition, the second question was addressed using a Fisher's Exact Test to look at the comparison of the proportion of siblings affected for each of the 10 questions on the family history questionnaire between receptive/expressive and pure expressive language delayed subjects in the SELD group. Results show a significant difference in the number of families with affected 
Table 6

z-Score and Percent of Families with Affected Siblings in

Receptive/expressive and Expressive Delayed SELD Groups

Families with

Affect ed

Goup

Number

Siblings/

z-score

Significance

Number of

level

Families

SELD

Receptive/

4

$4 / 4(100 \%)$

Expressive

SELD

Expressive

20

$10 / 20(50 \%)$

$* 4.47$

$p<.05^{*}$

*Significant beyond the .05 level of confidence. 
siblings between the two groups. A significantly higher proportion of receptive/expressive delayed subjects had families with affected siblings on questions $2,3,6 a, 6 b, 6 c$, and $6 f$. No significant difference was found for questions $4,5,6 d$, or $6 e$ (see Table 7).

Finally, question 2 was also addressed by using a chi square test to compare data among the three groups of subjects: normals, SELDs with receptive/expressive delay, and SELDs with expressive delay only - on each of the 10 questions. Results indicate a significant difference among the three groups. The receptive/expressive group of subjects are significantly more likely to have siblings affected in the following areas: (a) Question 2 late to start talking, (b) Question 3 - had speech therapy before entering school, (c) Question 6a - have trouble learning to read, (d) Question $6 b$ - have trouble learning to write, (e) Question $6 c$ - have trouble learning to spell, (f) Question 6f - receive special services in school. No significant difference was found in the categories of: (a) Question 4 - learning to put words together, (b) Question 5 pronouncing words, (c) Question 6d - learning mathematics, or (d) Question 6e - held back a grade (see Table 8). 
Table 7

Fisher's Exact Test Values For Each of 10 Questions on Family History Questionnaire For Two Groups

\begin{tabular}{|c|c|c|c|c|c|}
\hline Question & $\begin{array}{l}\text { Receptivel } \\
\text { expressive } \\
\text { Families } \\
\text { with } \\
\text { affected } \\
\text { siblings }\end{array}$ & $\begin{array}{l}\text { Percent } \\
\text { (aff ect ed } \\
\text { sibs/ tot al } \\
\text { f amilies) }\end{array}$ & $\begin{array}{l}\text { Expressive } \\
\text { only } \\
\text { Families } \\
\text { with } \\
\text { affected } \\
\text { siblings }\end{array}$ & $\begin{array}{l}\text { Percent } \\
\text { (affect ed } \\
\text { sibs/tot al } \\
\text { f amilies) }\end{array}$ & $\begin{array}{c}\text { Fisher's } \\
\text { Exact Test } \\
\text { Values }\end{array}$ \\
\hline 2 & 4 & $\begin{array}{c}4 / 4 \\
(100 \%)\end{array}$ & 3 & $\begin{array}{l}3 / 20 \\
(15 \%)\end{array}$ & $.003^{*}$ \\
\hline 3 & 4 & $\begin{array}{c}4 / 4 \\
(100 \%)\end{array}$ & 1 & $\begin{array}{l}1 / 20 \\
(5 \%)\end{array}$ & $.000^{*}$ \\
\hline 4 & 2 & $\begin{array}{c}2 / 4 \\
(50 \%)\end{array}$ & 3 & $\begin{array}{l}3 / 20 \\
(15 \%)\end{array}$ & .179 \\
\hline 5 & 3 & $\begin{array}{c}3 / 4 \\
(75 \%)\end{array}$ & 6 & $\begin{array}{l}6 / 20 \\
(30 \%)\end{array}$ & .130 \\
\hline $6 a$ & 3 & $\begin{array}{c}3 / 4 \\
(75 \%)\end{array}$ & 3 & $\begin{array}{l}3 / 20 \\
(15 \%)\end{array}$ & $.035^{*}$ \\
\hline $6 b$ & 3 & $\begin{array}{c}3 / 4 \\
(75 \%)\end{array}$ & 2 & $\begin{array}{l}2 / 20 \\
(10 \%)\end{array}$ & $.018^{*}$ \\
\hline $6 c$ & 3 & $\begin{array}{c}3 / 4 \\
(75 \%)\end{array}$ & 1 & $\begin{array}{l}1 / 20 \\
(5 \%)\end{array}$ & $.008^{*}$ \\
\hline $6 d$ & 1 & $\begin{array}{c}1 / 4 \\
(25 \%)\end{array}$ & 1 & $\begin{array}{l}1 / 20 \\
(5 \%)\end{array}$ & .312 \\
\hline $6 \theta$ & 0 & $\begin{array}{l}0 / 4 \\
(0 \%)\end{array}$ & 1 & $\begin{array}{l}1 / 20 \\
(5 \%)\end{array}$ & 1.000 \\
\hline $6 \mathrm{f}$ & 4 & $\begin{array}{c}4 / 4 \\
(100 \%)\end{array}$ & 4 & $\begin{array}{l}4 / 20 \\
(20 \%)\end{array}$ & $.007^{\star}$ \\
\hline
\end{tabular}

*Significant at the .05 level of confidence. 
Table 8

3-Way Chi Squared Comparison of Data For Three Groups on Each Question of the Family History Questionnaire

\begin{tabular}{|c|c|c|c|c|c|}
\hline Question & $\begin{array}{l}\text { NORMAL } \\
\text { Affected } \\
\text { Sibs/ } \\
\text { Total } \\
\text { Families }\end{array}$ & $\begin{array}{c}\text { RECEPI } \\
\text { EXPRESS } \\
\text { Affected } \\
\text { Sibs/ } \\
\text { Total } \\
\text { Families }\end{array}$ & $\begin{array}{l}\text { EXPRESS } \\
\text { ONLY } \\
\text { Affected } \\
\text { Sibs I } \\
\text { Total } \\
\text { Families }\end{array}$ & $x^{2}$ & $\begin{array}{c}\text { Signifi- } \\
\text { cance } \\
\text { Level }\end{array}$ \\
\hline 2 & $\begin{array}{l}4 / 21 \\
(19 \%)\end{array}$ & $\begin{array}{c}4 / 4 \\
(100 \%)\end{array}$ & $\begin{array}{l}3 / 20 \\
(15 \%)\end{array}$ & 13.60 & $p=.001$ \\
\hline 3 & $\begin{array}{l}1 / 21 \\
(4 \%)\end{array}$ & $\begin{array}{c}4 / 4 \\
(100 \%)\end{array}$ & $\begin{array}{l}1 / 20 \\
(5 \%)\end{array}$ & 28.53 & $p<.001$ \\
\hline 4 & $\begin{array}{l}4 / 21 \\
(19 \%)\end{array}$ & $\begin{array}{c}2 / 4 \\
(50 \%)\end{array}$ & $\begin{array}{l}3 / 20 \\
(15 \%)\end{array}$ & NS & \\
\hline 5 & $\begin{array}{l}8 / 21 \\
(38 \%)\end{array}$ & $\begin{array}{c}3 / 4 \\
(75 \%)\end{array}$ & $\begin{array}{l}6 / 20 \\
(30 \%)\end{array}$ & NS & \\
\hline $6 a$ & $\begin{array}{l}5 / 21 \\
(23 \%)\end{array}$ & $\begin{array}{c}3 / 4 \\
(75 \%)\end{array}$ & $\begin{array}{l}3 / 20 \\
(15 \%)\end{array}$ & 6.50 & $p=.0487$ \\
\hline $6 b$ & $\begin{array}{l}3 / 21 \\
(14 \%)\end{array}$ & $\begin{array}{c}3 / 4 \\
(75 \%)\end{array}$ & $\begin{array}{l}2 / 20 \\
(10 \%)\end{array}$ & 9.96 & $p<.05$ \\
\hline $6 c$ & $\begin{array}{l}3 / 21 \\
(14 \%)\end{array}$ & $\begin{array}{c}3 / 4 \\
(75 \%)\end{array}$ & $\begin{array}{l}1 / 20 \\
(5 \%)\end{array}$ & 12.48 & $p<.05$ \\
\hline $6 d$ & $\begin{array}{c}2 / 21 \\
(9.5 \%)\end{array}$ & $\begin{array}{c}1 / 4 \\
(25 \%)\end{array}$ & $\begin{array}{l}1 / 20 \\
(5 \%)\end{array}$ & NS & \\
\hline $6 e$ & $\begin{array}{c}1 / 21 \\
(4.7 \%)\end{array}$ & $\begin{array}{l}0 / 4 \\
(0 \%)\end{array}$ & $\begin{array}{l}1 / 20 \\
(5 \%)\end{array}$ & NS & \\
\hline $6 \mathrm{f}$ & $\begin{array}{l}4 / 21 \\
(19 \%)\end{array}$ & $\begin{array}{c}4 / 4 \\
(100 \%)\end{array}$ & $\begin{array}{l}4 / 20 \\
(20 \%)\end{array}$ & 12.07 & $p<.05$ \\
\hline
\end{tabular}




\section{Discussion}

The purpose of this study was to investigate whether there was a significant difference between the siblings of two groups of children, those with slow expressive language delay (SELD) and a normally speaking group in terms of reported language problems. The siblings of the subjects were studied, using a family history questionnaire asking parents to report on 10 questions of language and related problems. This study also looked for a significant difference in the proportion of siblings affected with language problems in subjects with expressive/receptive language disorders at intake as compared to those with pure expressive language deficits at induction to the original study.

The results of this investigation revealed a significant between-group difference on one question of the family history questionnaire. Siblings of language disordered subjects were significantly more likely to have speech therapy before entering school (question 3) than were siblings of normal speakers.

Data from this study also revealed that there was a significant difference in probability of family history of language and related disorders in SELD subjects with receptive/expressive language delays at intake compared to those SELD subjects with pure expressive deficits at that time even though all subjects scored within the normal range on receptive skills by school age. These 
data support the hypothesis proposed by Whitehurst et al. (1991) that language disorders may be more likely to have a genetic component when the sample population has a language delay with a receptive component. As Whitehurst and associates (1991, 1992) suggested, pure expressive language delays do not appear to be associated with family history when subjects with a receptive component are removed from the sample. This suggests, as Whitehurst and associates $(1991,1992)$ purposes, expressive language delay in and of itself may not be a pathology but simply a developmental difference. Delays with a receptive component, however, may be a factor in language disorders that are inherited among siblings. As stated earlier, most researchers tend to agree that language impairments run in families, particularly in siblings of language disordered children. These data add further evidence in support of the inheritability of language disorders and specifically emphasizing this link in the group of subjects with receptive/expressive language delay at an early stage of development.

A significant difference was found between SELD subjects with receptive/expressive language disorders and those SELD subjects with expressive only language disorders on 6 of 10 questions on the family history questionnaire. A significantly higher proportion of receptive/expressive delayed SELD subjects had siblings affected in the following areas: late to start talking (question 2), speech therapy before entering school (question 3), 
learning to read (question 6a), learning to write (question 6b), learning to spell (question 6c), and received special services in the schools (question 6f). The areas that did not reveal a significant difference between groups were: learning to put words together (question 4), problems pronouncing words (question 5), learning math (question 6f), and held back a grade (question 6e). If the receptive/expressive group were more closely matched in size to the 20 subjects in the expressive only SELD group, a significant difference may have been found in this areas.

When looking at the three groups; normal, receptive/expressive SELD, and expressive only SELD, a significant difference was found on 6 of the 10 questions on the family history questionnaire. The receptive/expressive SELD group of subjects was found more likely to have families with affected siblings in these six categories: late to start talking (question 2), speech therapy before entering school (question 3), trouble learning to read (question 6a), trouble learning to write (question 6b), trouble learning to spell (question 6c), and received special services in the schools (question 6f). These data further support Whitehurst et al.'s (1991) notion that a disorder with a receptive component is more likely to involve genetic factors than is a circumscribed expressive disorder.

There are several limits to this study that warrant discussion. Sample size of 20 normal and 24 delayed subjects is small, limiting results of this study to preliminary and in need of further study. As 
mentioned, the receptive/expressive SELD group contains 4 subjects with 6 siblings, which is disproportionate to the 20 subjects in the expressive only SELD delayed group with 29 siblings.

Direct testing of siblings of study subjects was not done due to time and cost factors. Parent report is a reliable method of data collection according to Tallal et al. (1989). However, some parents may have had a more accurate memory of past events than others and this could have influenced the results.

Age of siblings could also have affected findings. Since study subjects were young, many tended to have younger brothers and sisters. These siblings may have been too young to be identified with a language disorder despite one's being present.

The questionnaire was comprised of 10 questions on communication delays, designed to provide information on history of speech and language development in siblings of study subjects. Information was also gathered on academic achievement in the areas of reading, spelling, writing, and mathematics. Siblings of language disordered subjects, particularly SELD subjects with receptive/expressive language delay, appear to present language problems that affect early language development. Based on responses to the family history questionnaire, these siblings have language delays that affect learning speech and continue through the early stages of learning to read, write, spell, and/or learn mathematics. It is not known from the parent response to the questions if these areas continue to be problems or if siblings have 
mastered these skills and caught up with their classmates. The data also suggest that receptive language delays tend to disappear as children mature, indicating that in this area of language, children tend to catch up to their peers. Further study of the siblings with language delay and their long term outcome in academic achievement is an area in need of exploration. 
CHAPTER V

SUMMARY AND IMPLICATIONS

Summary

Researchers are seeking more information on how and why language disorders tend to run in families, particularly siblings of language disordered children.

This study addressed two questions. First, it attempted to determine whether a significant difference in prevalence of language problems exists in the siblings of two groups of children: those with SELD and those with a normal language history. The second question this study sought to answer was: Is there a greater probability of language problems in the siblings of subjects within the SELD group who have early receptive/expressive language disorders when compared to SELD subjects with pure expressive language deficits.

Subjects used in this study were 457 year-old children participating in a longitudinal study at Portland State University. The Reynell Language Development Scale (1984) was administered at intake, when the children were approximately 24 months of age and was used to identify children with receptive/expressive and pure expressive language delays. When the subjects entered 2nd grade 
and were 7-8 years of age, the Test of Language Development Primary-2 (TOLD-2) (1988) was administered to determine receptive language development. It appears that differences in receptive language become less apparent between subject groups at this age and all subjects scored within the normal range on this measure. This may indicate that a receptive component affects early language development in children with language delay, as Whitehurst et al. (1991) proposed. These children appear to catch up to their peers in the area of receptive language when they reach 7 to 8 years of age. The instrument used to acquire data for this study was a family history questionnaire, listing ten questions pertaining to speech, language, and academic delays such as learning to read, write, spell, and learn mathematics. Parents were asked to report on the presence of language problems in the full siblings of children in the study.

In answering the first question posed, results of a one-sided z-test of proportions indicated a significant difference in the number of families with affected siblings between the SELD group of subjects and the subjects with a normal language history. The 10 questions on the family history questionnaire were looked at individually. Siblings of the SELD subjects were more likely than siblings of subjects from the normal group to have had speech therapy before entering school (question 3). No significance between groups was found on the remaining 9 categories of language problems. 
Addressing question two, a one-sided $\underline{z}$-test indicated a significant difference in reported language history between the two subgroups of SELD subjects; those with early receptive/expressive language delays and those with pure expressive language delays, as measured by The Reynell Developmental Language Scale (1984). Siblings of the SELD subjects in the receptive/expressive delayed group were more likely to have a reported history of overall language problems as indicated by a positive response on any of the ten questions of the family history questionnaire when compared to the SELD expressive language delayed group.

Question 2 was further explored by looking at the proportion of families with affected siblings on each of the 10 questions on the family history questionnaire between the receptive/expressive and expressive language delayed subgroups within the SELD group. Results of a Fisher's Exact Test indicate a significant difference at the .05 level of confidence in six out of ten questions on the family history questionnaire (question numbers $2,3,6 a, 6 b, 6 c$, and 6f). Siblings of the SELDs with receptive/expressive delays were more likely to have language or related problems when compared to the SELDs with expressive delays only on these questions. No significance was found for item numbers $4,5,6 d$, or $6 e$.

Question 2 was also addressed with a chi square test of difference. This measurement was used to compare the three groups of subjects: normal, SELDs with receptive/expressive delay, and SELDs with pure expressive language delay on each of the 10 
questions of the family history questionnaire. Results indicate a significant difference between the three groups on questions 2,3 , $6 a, 6 b, 6 c$, and $6 f$, showing the SELD group with receptive/expressive delay to be more likely to report problems in these areas. Results for questions $4,5,6 \mathrm{~d}$, and $6 e$ found no significant relationship.

\section{Clinical Implications}

Results of this study indicate that there is a significant difference in reported language problems between the siblings of subjects with a normal language history and an SELD group of subjects. Language problems in siblings are defined to mean a positive parent report on ten questions of the family history questionnaire covering speech and language development and the academic areas of reading, writing, spelling, and mathematics. Further, when the SELD subjects are divided into two groups of receptive/expressive language delay and pure expressive language delay, a significant difference was found to exist, with a higher proportion of families with affected siblings in the receptive/expressive delayed group.

These results may indicate that a receptive language component is associated with the heritability of specific language disorders among children. If a child with a receptive/expressive 
language disorder has brothers and/or sisters in the family, they may be more likely to share a language disorder. The results of this study may point to the significance of family history information.

It appears that pure expressive disorders do not raise the risk for language problems in siblings. However, siblings of subjects with receptive/expressive language delay are more likely to experience problems with language development and have problems in the academic areas of learning to read, write, spell, and learn mathematics than siblings of subjects with pure expressive language delay. Screening procedures may be done for these children whose parents report a history of receptive/expressive language delay in older brothers and sisters. Particular attention may be needed when these children reach school age, allowing for extra assistance and/or special individualized instruction to master the tasks of reading, spelling, writing, and mathematics.

Research Implications

Further research into the question of heritability of specific language disorders is warranted. Differentiating specific types of language disorders, using a larger sample size, severity levels, and/or use of direct testing of siblings may relate further patterns of inheritance and types of language disorders that tend to occur in families of language impaired children. 
Language disorders change over time and can lead to problems such as learning disabilities and reading impairments, hindering academic achievement. This investigation produced evidence in support of this statement, with a higher proportion of SELD subjects, particularly those with a receptive component, reporting speech, language, and/or academic problems in siblings. The loss of a receptive component of language disorder as the children matured was also discussed. This should be further studied to determine the transitory nature of language disorders in children. Do siblings of SELD subjects continue to have problems with reading, writing, spelling, and mathematics? The use of direct testing of siblings of study subjects should be investigated further to help determine the inheritability of language delays. Does gender affect history of language delay? Further research addressing these issues may help to identify a risk factor in the transmission of language delay in siblings of language delayed subjects. 


\section{REFERENCES}

Hardy-Brown, K., Plomin, R., \& DeFries, J. C. (1981). Genetic and environmental influences on the rate of communicative development in the first year of life. Developmental Psychology, 17 (6), 704-717.

Lewis, B. A., Ekelman, B. L., \& Aram, D. M. (1989). A familial study of severe phonological disorders. Journal of Speech and Hearing Research, 32, 713-724.

Lewis, B. A. \& Thompson, L. A. (1992). A study of developmental speech and language disorders in twins. Journal of Speech and Hearing Research, 35, 1086-1094.

Ludlow, C. L. \& Cooper, J. A. (1983). Genetic aspects of speech and language disorders. New York: Academic Press.

Matheny, A. P., \& Bruggemann, C. E. (1973). Children's speech: Heredity components and sex differences. Folia Phoniatrica, 25. 442-449.

Mather, P. L. \& Black, K. N. (1984). Hereditary and environmental influences on preschool twins language skills. Developmental Psychology, 20 (2), 303-308. 
Myers, J. K. \& Bean, L. L. (1968). A decade later: A follow-up of social class and mental illness. New York: Wiley and Sons.

Neils, J., \& Aram, D. M. (1986). Family history of children with developmental language disorders. Perceptual and Motor Skills, $\underline{63}$, 655-658.

Newcomer, P. L. \& Hammill, D. D. (1988). Test of Language Development-2 (Primary). Pro-Ed, Austin, Texas.

Paul, R. (1991). Profiles of toddlers with slow expressive language development. Topics in Language Development, 11 (4),

Rescorla, L. (1989). The Language Development Survey: A screening tool for delayed language in toddlers. Journal of Speech \& Hearing Disorders, 54, 587-599.

Reynell, J. (1984). Developmental Language Scale. London: NFER Nelson.

Tallal, P., Ross, R., \& Curtis, S. (1989). Familial aggregation in specific language impairment. Journal of Speech and Hearing Disorders, 54, 167-173. 
Tomblin, J. B. (1989). Familial concentration of developmental language impairment. Journal of Speech and Hearing Disorders $\underline{54}$. 587-595.

Tomblin, J. B., Freese, P. R., \& Records, N. L. (1992). Diagnosing specific language impairment in adults for the purpose of pedigree analysis. Journal of Speech and Hearing Research, 35, 832-843.

Whitehurst, G. J., Arnold, D. S., Smith, M., Fischel, J. E., Lonigan, C. J., \& Valdez-Menchaca, M. C. (1991). Family history in developmental expressive language delay. Journal of Speech and Hearing Research, 34, 1150-1157.

Whitehurst, G. J., Fischel, J. E., Arnold, D. S., \& Lonigan, C. J. (1992). Evaluating outcomes of children with expressive language delay. In S. F. Warren and J. Reichle (Eds), Causes and effects in communication and language intervention. (pp.277-308). Baltimore, MD: Paul H. Brookes Publishing Co. 
APPENDIX A

OREGONIAN ARTICLE 


\section{Toddlers with delayed speech sought}

A Portland State University researcher is looking for otherwise normal toddlers who begin talking late to serve as subjects in a study of delayed speech and its connection, if any, to later language problems.

Rhea Paul, a PSU assistant professor of speech communication, said the reasons for delayed speech in "late-blooming" young children and the early identification of toddlers who later will suffer chronic language delay had not been well-investigated, although perhaps 10 percent of American children may fall into those categories.

Paul is interested in studying children between the ages of 18 and 30 months in the Portland-Vancouver area who can say only five or fewer words, instead of the 50 or so most children can speak by that age. She hopes to monitor their progress in speech development for two to five years, using such tools as speech tests and videotaped play sessions with their parents, to determine whether the children are indeed late-bloomers or whether their lack of early communication skills signals the start of severe speech and language delays.

Early identification of such children may allow early intervention and prevent future speech deficits, she said.

Paul's research is funded by the Fred Meyer Charitable Trust, the American Speech, Language and Hearing Foundation, and PSU. Parents who are interested in allowing their children to participate may contact Paul through the PSU Department of Speech.

The Oregonian, Portland, Oregon 
APPENDIX B

LANGUAGE DEVELOPMENT SURVEY 


\section{Language Development Survey}

Plcase check off each word that your child says SPONTANEOUSLY (not iust imitates or understands) It's okay to count words that aren't pronounced clearly or are in "baby talk" ("baba" for bottle.)

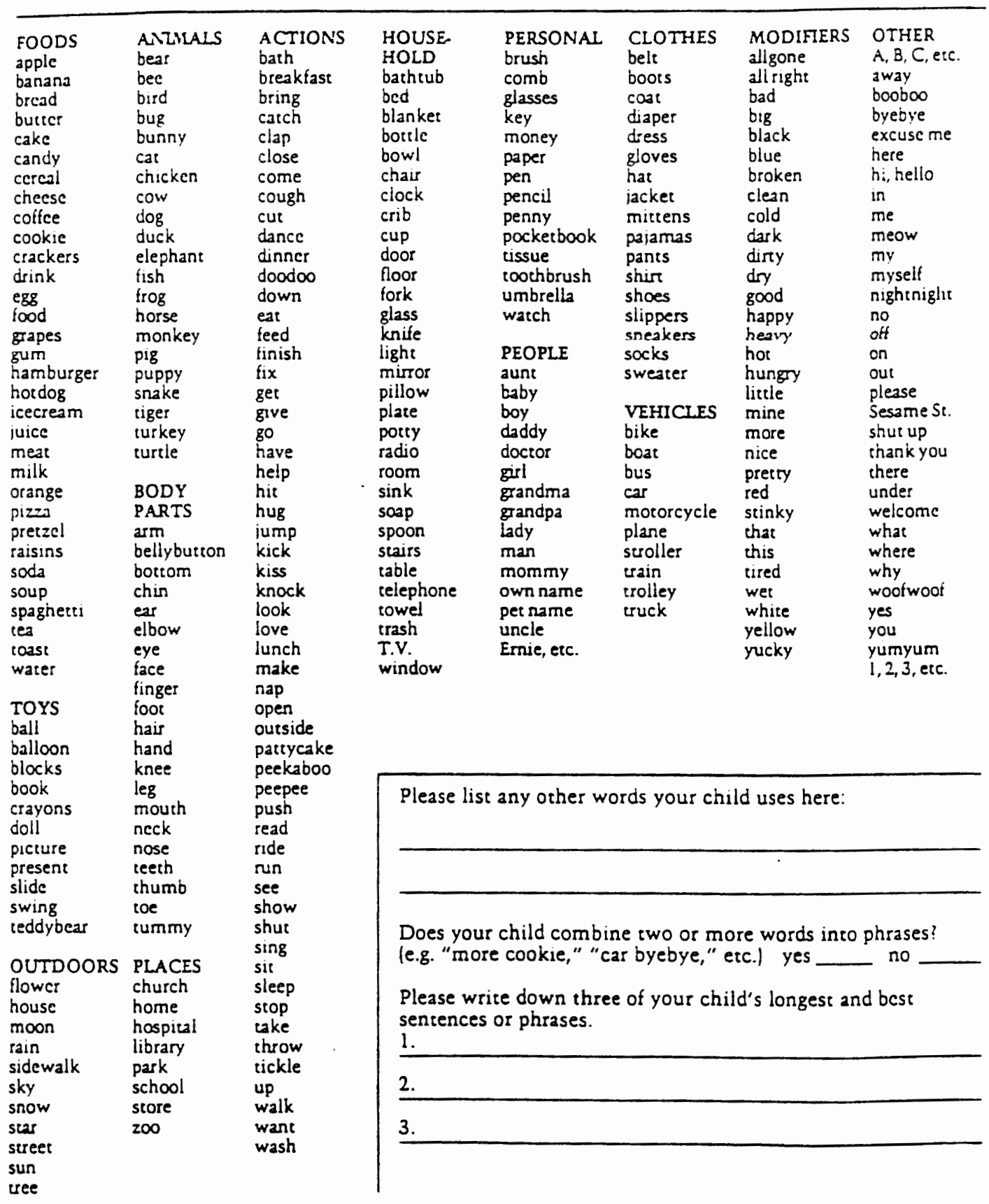


APPENDIX C

FAMILY HISTORY QUESTIONNAIRE 
Subject ${ }^{*}$

Date

1 How many siblings does the child have? (please list names and current age for each) males. females

2 How many were late to start talking?

male(s) female(s)

3 How many had speech therapy before entering schonl?

male(s)

4 How many had trouble learning to put words together to make sentences"

female(s)

male(s) femalers

5 How many had problems pronouncing words and/or were hard to understand?

6. How many siblings are of school age? female(s)

Ga Of those siblings, how many had trouble learning to read? female(s) maleis)

6b. How many had trouble learning to write? femaleis male(s) oc. How many had trouble learning to spell? female(s)

6d. How may had trouble learning mathematics? female(s) male(s) femalers!

Ge How many were held back a grade? male(s)

6f How many received special services in the schools" female(s) male(s) female(s)

Please ante with an asterisk $(*)$ if any of the above siblings are half-brothers or half-sisters $w$ the child participating in the project 
APPENDIX D

INFORMED CONSENT 
INFORMED CONSENT

1 . agree to take part in this research project, which is a follow-up study on the Portland Language Development Project I understand that this follow-up study involves answering questions via a mailed question naire form pertaining to the brothers and sisters of the child in the above named longitudinal study

I understand that because of this study, there are no risks. hazards or inconveniences

Carol Unkefer, Graduate Student, has told me that the purpose of the study is to obtain more information on the language or related disorders of brothers and sisters of the child in the above named study

I may not receive any direct benefit from taking part in this study. But the study may $\mathrm{k}$.lp to increase knowledge that may help others in the future

She has promised that all information I give will be kept confidential to the extent permitted by law. and that the names of all people in the study will also be kept confidential

I understand that I do not have to take part in this study

I have read and understand the above information and agree to take part in this study

Date Signature 
APPENDIXE

HUMAN SUBJECTS RESEARCH FORM 


\section{OFFICE OF RESEARCH AND SPONSORED PROJECTS}

DATE: July 12,1993

TO: Carol Unkefer :

FROM: $\quad$ Martha Balshem, Chair, HSRRC 1993-94 Ma.Tla Bulsheul/Aul

RE: HSRRC Approval of Your Application titled "Is there a significant difference..."

In accordance with your request, the Human Subjects Research Review Committee has reviewed your proposal referenced above for compliance with DHHS policies and regulations covering the protection of human subjects. The committee is satisfied that your provisions for protecting the rights and welfare of all subjects participating in the research are adequate, and your project is approved.

Any changes in the proposed study, or any unanticipated problems involving risk to subjects, should be report d to the Human Subjects Research Review Committee. An annual report of the status of the roject is required.

c. Office of Graduate Studies 
APPENDIX F

RAW DATA 
Questions

with Affected

Subject No.

Sibs on

Reynell

TOLD-2 Family

Group- Receptive No. Words on Listening History

Normal $\underline{z}$ - Scores LDS Quotient Questionnaire

$\begin{array}{lcccc}032 & -0.3 & 247 & 81 & 6 \mathrm{~d} \\ 036 & 1.7 & 235 & 109 & 0 \\ 040 & 0.3 & 213 & 106 & 2,3,4,5,6 \mathrm{f} \\ 050 & 0.3 & 203 & * & 0 \\ 051 & -1.6 & 67 & 113 & 5,6 \mathrm{a}, 6 \mathrm{c}, 6 \mathrm{e} \\ 055 & 0.0 & 325 & 102 & 2,4,5 \\ 058 & 0.8 & 263 & 111 & 0 \\ 059 & 1.1 & 263 & 109 & 0 \\ 072 & 0.3 & 145 & 104 & 6 \mathrm{a}, 6 \mathrm{~b}, 6 \mathrm{c}, 6 \mathrm{f} \\ 095 & -0.8 & 11 & 96 & 6 \mathrm{a}, 6 \mathrm{~b}, 6 \mathrm{f} \\ 113 & 2.8 & 257 & 109 & 0 \\ 128 & 1.3 & 247 & 102 & 0 \\ 129 & 1.9 & 275 & 106 & 5,6 \mathrm{a}, 6 \mathrm{~b}, 6 \mathrm{c} \\ 130 & 0.4 & 222 & 117 & 0 \\ 131 & 0.4 & 257 & 89 & 2,4,5,6 \\ 132 & 0.5 & 102 & 115 & 0 \\ 133 & 0.6 & 239 & 111 & 0\end{array}$


Questions

Group- Reynell

TOLD-2 with Affected

Normal Receptive No. Words on Listening Sibs on Family

(cont'd) z- Scores LDS Quotient History

Questionnaire

\begin{tabular}{lcccc}
\hline 138 & 0.7 & 96 & 89 & 0 \\
139 & 2.8 & 274 & 121 & 0 \\
141 & 1.9 & 173 & 115 & 0 \\
144 & $*$ & 197 & 119 & 5
\end{tabular}

SELD

Express

Only

$\begin{array}{lcccc}012 & 0.9 & 44 & 106 & 5,6 \mathrm{a}, 6 \mathrm{~b}, 6 \mathrm{f} \\ 057 & 0.9 & 20 & 100 & 2,3,4,5,6 \mathrm{f} \\ 084 & 0.3 & 2 & 111 & 0 \\ 086 & 0.5 & 69 & * & 6 \mathrm{c} \\ 087 & 1.1 & 5 & 117 & 2,5 \\ 090 & -0.2 & 6 & 96 & 0 \\ 091 & 0.0 & 16 & 81 & 2 \\ 092 & 0.5 & 45 & 117 & 0 \\ 094 & 0.8 & 23 & 100 & 5,6 \mathrm{f} \\ 097 & 0.8 & 12 & 102 & 6 \mathrm{a}, 6 \mathrm{e}, 6 \mathrm{f} \\ 098 & 0.2 & 5 & 113 & 0 \\ 100 & 0.7 & 27 & 100 & 5\end{array}$




\begin{tabular}{ccccc}
\hline $\begin{array}{l}\text { SELD } \\
\text { Express }\end{array}$ & $\begin{array}{c}\text { Reynell } \\
\text { Only }\end{array}$ & $\begin{array}{c}\text { No. Words } \\
\text { Receptive } \\
\text { on LDS }\end{array}$ & $\begin{array}{c}\text { TOLD-2 } \\
\text { Listening } \\
\text { Quotient }\end{array}$ & $\begin{array}{c}\text { Questions } \\
\text { with Affected } \\
\text { Sibs } \\
\text { on Family } \\
\text { History }\end{array}$ \\
\hline 102 & 0.0 & 81 & 102 & Questionnaire \\
\hline 103 & 1.1 & 15 & 100 & 0 \\
105 & 0.0 & 7 & 119 & $4,5,6 \mathrm{~b}, 6 \mathrm{~d}$ \\
109 & 0.3 & 25 & 126 & 0 \\
111 & 0.7 & 13 & 106 & 4 \\
112 & -0.2 & 35 & $*$ & 0 \\
119 & 1.9 & 2 & 134 & 0 \\
142 & 1.9 & 5 & 100 & 0 \\
SELD Recl & & & &
\end{tabular}

\section{Express}

Delayed

$\begin{array}{ccccc}006 & -2.7 & 8 & 104 & 2,3,6 \mathrm{~b}, 6 \mathrm{~d}, 6 \mathrm{f} \\ 007 & -2.0 & 9 & 106 & \begin{array}{c}2,3,5,6,6 \mathrm{a}, \\ 6 \mathrm{~b}, 6 \mathrm{c}, 6 \mathrm{f}\end{array} \\ 029 & -1.7 & 14 & 102 & \begin{array}{c}2,3,4,5,6 \mathrm{a}, \\ 093\end{array} \\ & -1.3 & 22 & 98 & 2,4,5,6 \mathrm{a}, 6 \mathrm{~b}, \\ & & & & 6 \mathrm{c}, 6 \mathrm{f}\end{array}$

*Subject did not participate in this portion of study this year 